\title{
The Name Game
}

\section{Meghann Clark}

It is Monday. Cars fly by noisily as Emily strolls down the main road. When she waits for the tram, it is always in the same place. She has developed a liking for isolation. It holds a unique sense of peace that she seeks out anywhere she can. A secluded bench, shaded by familiar leafy trees provides privacy during her daily wait for the ninety six. Emily flicks open her book and spends ten minutes alone and lost in a romance between a French poet and an American waitress.

On Tuesday a dull luminosity coats the trees, people and traffic. Emily approaches her bench and finds a girl is there, busily scribbling in a notebook. In Emily's two years of living in the same house, going to the same tram stop, this has never happened before. She does not know how to respond to this change in scene, this interruption. After an internal debate, she begrudgingly decides to sit on the bench regardless of the stranger. As she waits the ten minutes for her tram, Emily is half immersed in her book and half pondering this queer girl with the pointed fabric shoes.

Weeks roll by. Every morning, Emily is forced to sit beside this girl on the once lonely bench. Emily reads less, and takes to observing this stranger. The girl is tall, graceful with shiny brown hair. Her lips are thin, but always twisted into an attractive expression. Her clothing is erratic, straw hats and bright skimpy dresses. She can't help but watch this girl. On the tram, people seem to suffer the same curiosity. Men openly stare, women glance with as much subtlety as possible and children peer shyly over the tops of seats giggling hysterically when she winks at them. 
On a warm Wednesday evening, Emily gets off the tram and bumps straight into her bench partner, sending her notebook and pencil case flying.

'You're the girl from the bench, yeah?'

Emily nods cautiously. The girl smiles and steps forward. 'Clare,' she says brightly, extending a small hand of painted red nails.

Over the week the girls go from silence, to quiet acknowledgement, to something pending definition that Emily could not have predicted.

Emily stands and approaches the sliding doors of the tram which will shortly open at her stop.

'I'm not getting off here sweetheart,' Clare laughs with a grin. 'I've got more yellow notes than I should and I do so feel like a bit of fun. Listen, come with me into the city?

The tram grinds to a halt, and a long beep sounds as the tram doors slide open.

'Emily, we'll play a game. Everywhere we go we can be somebody else. Perhaps Kate ... Perhaps Sarah. You'd like that, wouldn't you sweetheart?' Clare almost croons her last words, and Emily sees understanding there.

The doors slide shut and Emily sits back down next to Clare, who is wearing her best mysterious smirk as the tram glides through blurry streetlights.

The tram stops in the city and Clare leads Emily into a modest looking brick pub. The carpets are a royal red blemished with liquor stains. They fill jug upon jug with beer, sharing to cut the costs, and slowly Emily loses her inhibitions. Clare just laughs louder, Emily isn't sure that Clare has even heard of inhibitions.

They catch another tram. Emily is intrigued by the dishevelled characters on board. Businessman frown condescendingly and women clutch their purses nervously. Clare however plonks herself right next to the nearest of the grubby looking people.

'What's your name?' she says brightly. The man has a thick wiry beard glittering with webs of saliva. He smells like tacos and urine. He tries to answer her, waves his arms slowly and mumbles. Clare proceeds to tell this man how lovely she thinks it is that he collects cans, that recycling is important. Emily is not sure if this man can understand Clare, but sometimes the sides of his eyes crinkle, perhaps happily. Clare tells the man that her name is 'Sandy' and introduces Emily as 'Jane'. They get off 


\section{Meghann Clark}

the tram, and wave goodbye to the man from the street.

They are now in a club. The lights are dim. People sit at low glass tables, spilling drinks on one another. In the centre of the room, the roof is removed and there is a cluster of people dancing to loud fast music, pointing their hands up to the night sky. Clare and Emily join the cluster of people and dance together, everybody is friendly. They stumble over to an empty booth with some of the dancers and drink heavily. Eventually the bartender approaches the table and looks straight at Emily.

'What's your name, darling?'

Emily's eyes are laughing and glassy. She smiles at him. 'Rachel. My name is Rachel.'

He leans over, very close to her face and whispers into her hair. 'Well, Rachel, I think you've had a wee bit much to drink. All of you, get out.'

The dancers, Emily \& Clare, laughing all the way, stumble past the bartender into the night.

The breeze is crisp, the warm air emanating from the fire - twirling, twirling, twirling - slices through it like a knife. Clare and Emily are now lying in a park, running their hands numbly through the damp grass. Their new friends, the dancers, live nearby. Two shirtless men with messy hair stand metres away effortlessly spinning fire sticks. They weave in and out of the dark leafy trees while their audience squeals and sighs with admiration. To these friends, Emily has dubbed herself 'Georgia' and Clare is 'Tess'.

'Emily,' Clare whispers in a barely audible slur. 'Emily I'm really glad you came tonight.'

Emily laughs and nods slowly, fingers still streaming through the cool, green grass. They rise slowly and secretly, skulking away from the group onto the street. All the way home, they skip, and fall down. Emily finds a branch on the footpath and begins to twirl it as though it were alight. Clare laughs at the spectacle, and picks up the stick for Emily every time she drops it.

It is Monday. Clare didn't leave a note, or an email, or a phone number and Emily has not seen her since. On the tram, Emily sketches. A little girl peeks over her shoulder and says she would like a picture of an ice cream.

Emily draws a picture of the ice cream, only it has pig tails. The little girl squeals with delight and says the ice cream has hair just like hers. A 
boy has been watching her, Emily thinks she has seen him before and smiles.

The boy sits next to her with a quizzical expression. He remains silent. A few stops later Emily stands to leave the tram. Just as her feet hit the pavement, she hears the boy speak.

'I see you around, you know ... I was just wondering what your name was?'

Emily turns back, laughing, 'My name is Clare ... call me Emily if you like.' 


\section{An Uncertain Future}

\section{Geoff Goodfellow}

I was sitting in my car opposite

the Adelaide Magistrates Court

waiting on a change of lights

when i first saw her

she was in her early twenties

had on a black sleeveless top

$\&$ a denim mini skirt

her arms \& legs were heavily

tanned \& she wore strappy sandals

her hair was bottle blonde-

$\&$ as she crossed in front of me

blowing out a stream of blue

cigarette smoke

i noticed her black roots

complimented her chipped \& broken

front teeth

she was at least seven months pregnant

the lights changed

i moved off slowly-

into my own uncertain future. 